\title{
The media space of the educational sphere as a logistic system: features of management and personality formation
}

\author{
Denis Ermolatiy ${ }^{1 *}$, Kirill Pitelinskiy ${ }^{2}$, and Marina Saltykova ${ }^{3}$ \\ ${ }^{1}$ RANEPA, Moscow, Russia \\ ${ }^{2}$ Moscow Polytechnical University, Moscow, Russia \\ ${ }^{3}$ Civil Defence Academy, EMERCOM of Russia, Khimki, Russia
}

\begin{abstract}
Development of digitization (including education) leads to difficulties in management and regulation of important multidimensional dynamic social economical systems, where problems of efficient management occur requiring for interdisciplinary approach and active application of information technologies and computers. It is required to develop new methods of risk management (in the fields of national security, personal security), since information nonmilitary action as the most important hazard of hybrid wars is precepted as motion along the road of progress, democracy, tolerance. The research objective implies search and implementation of optimum management of stepwise digitization of education by means of monitoring and reconfiguration of digital platforms as elements of global logistic system (with consideration for consciental risks). Targets include analysis of features of dynamics and management of digitization of educational platforms in relation with maturity of social institutions, COVID-19, ecology of information space, degree of informatization of society, role and composition of mental structures, etc.; detection of factors influencing dynamics of persons and social institutions involved in education. The interrelation between digitization of education and development of educational platforms has been described. The conclusions have been made about the advantages and disadvantages of management formed by analogy with management of dynamic processes running on classical logistic systems. Recommendations have been given on how to reduce the dependence of a human on behavioral stereotypes imposed by various algorithmic energy information structures. In the frames of community, this would provide productive existence in unique personal space, efficient communication with surrounding people together with preservation of mentality and selfconsciousness, cultural and national identity.
\end{abstract}

Keywords: media space of education, information hazards, contour flows, information ecology.

\footnotetext{
* Corresponding author: denis.yermolatiy@yandex.ru
} 


\section{Introduction}

The world is facing a massive disaster: COVID-19, which varied existence, economy, global educational processes, etc. The lockdown has confirmed stability, operability and consistency of IT sector; its influence increased since the IT development in Russia and the world before occurrence of COVID-19 created a safety bag against consequences of pandemic.

Previously distance (electronic) learning was aimed at students, i.e., at convenient acceptance of assignments. This is good only for self-learning or in advanced training. The consciental educational paradigm is aimed at obtaining reliable education results (with high portion of residual knowledge, skills, habits, competences, as well as formed personality); however, in the era of electronic nomads, artificial intelligence and global digitization, it has become outdated $[1,2]$.

Variation of professionally stipulated multidimensional world, where pedagogically reasonable directional and organized interaction of subjects takes place, stipulates deployment of media space of educational entity [3]. Such process is a vector of development of education [4] and program-targeted horizon of planning results of teachers' activity.

Media space is a communication electronic environment formed by information and communication technologies, where organizations, groups, and communities can act simultaneously and jointly [5]. Table 1 summarizes the Russian digital platforms providing learning tools and didactic materials (usually of school level) [6].

Table 1. Russian digital education platforms.

\begin{tabular}{|c|c|}
\hline $\begin{array}{c}\text { Starting year of operation as } \\
\text { digital education platform }\end{array}$ & Name of the platform \\
\hline 2007 & Dnevnik.ru \\
\hline 2009 & Foksford \\
\hline 2010 & Novyi disk \\
\hline 2012 & Edu.Skyeng \\
\hline 2012 & Uchi.ru \\
\hline 2013 & YaKlass \\
\hline 2014 & InternetUrok.ru \\
\hline 2014 & MEO \\
\hline 2017 & Foksford \\
\hline 2017 & Prosveshchenie \\
\hline 2019 & Lecta \\
\hline
\end{tabular}

Prior to the lockdown the Russian digital platforms were being developed, occupying an important position in education system. The increase in their number demonstrated the interest of society in such tools and environments of development of school content (Fig. 1). Proportionally to the increase in variety of Russian digital educational platforms, their influence on education in total and their funding increased (Fig. 2) [7]. 


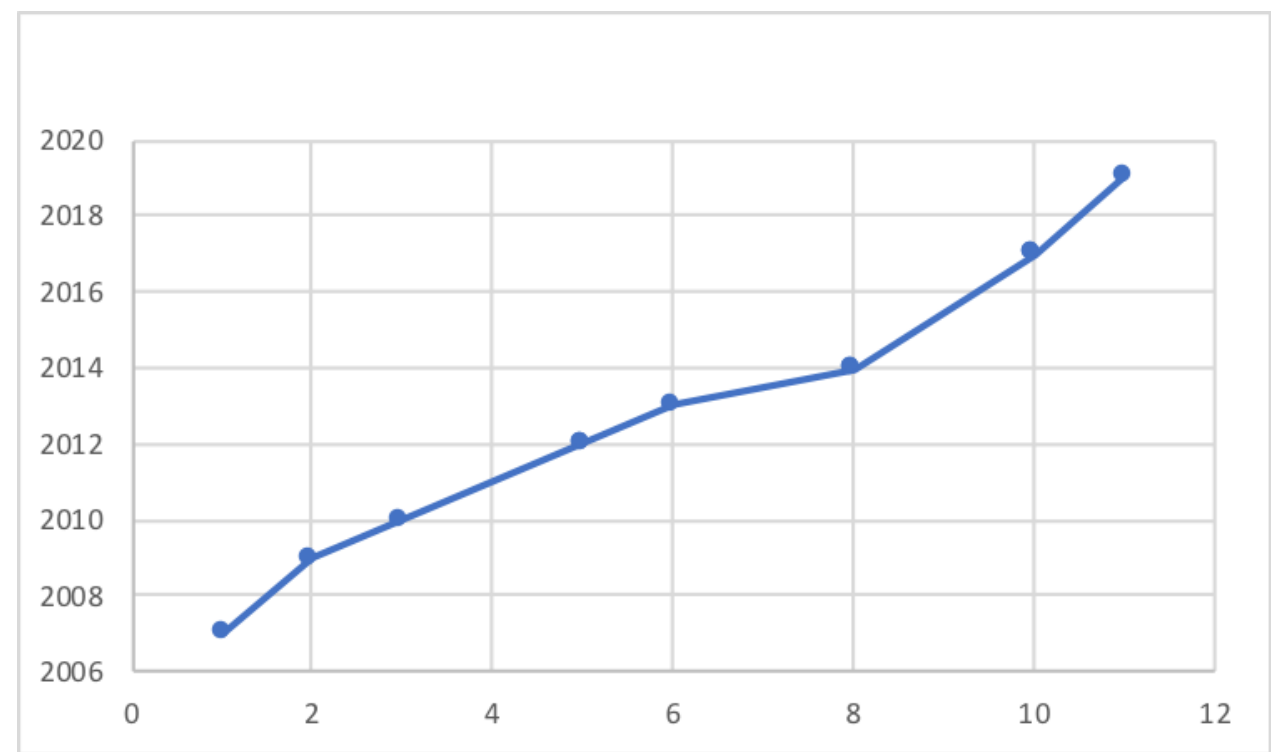

Fig. 1. Increase in the number of digital education platforms in Russia.

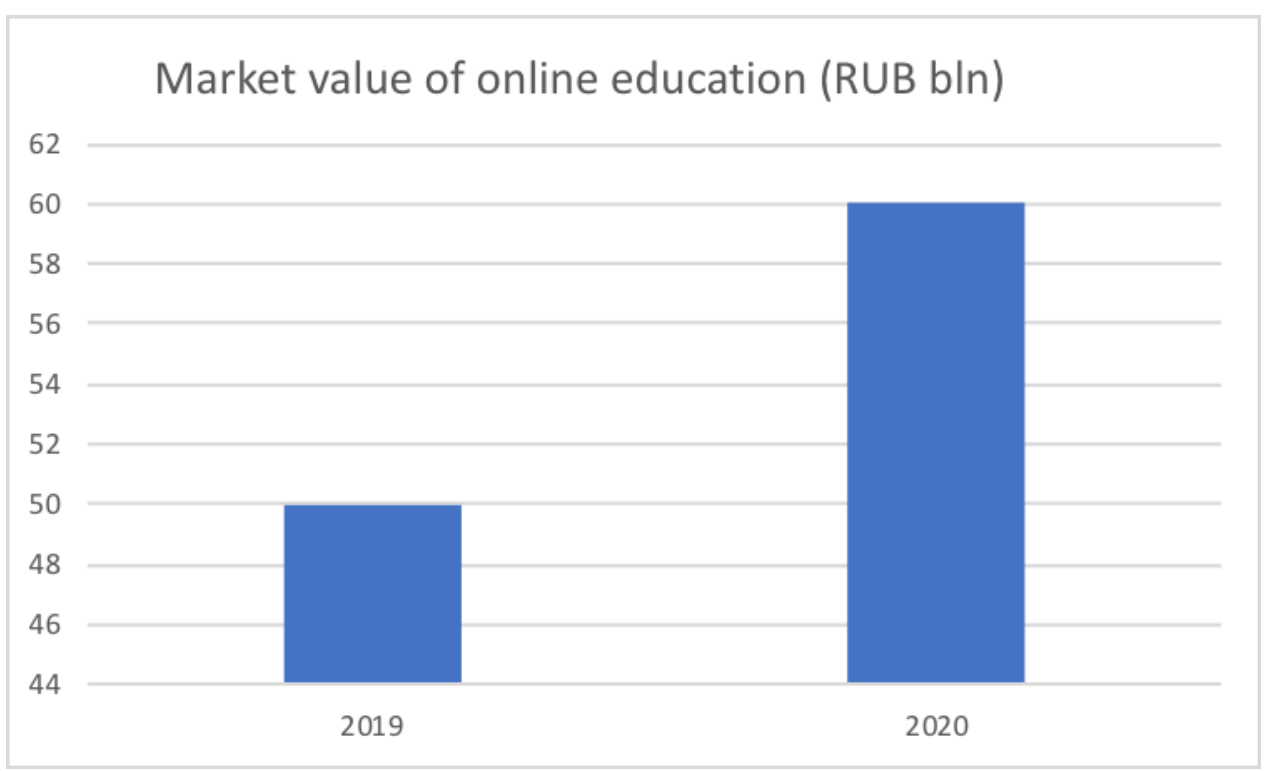

Fig. 2. Increase in the scope of education online programs in Russia in 2020.

\section{The concept of educational media space}

The increase in the number of digital platforms in the world (Google Class, Moodle, etc.) and in Russia as peculiar nodes of educational system of the 21 st century was accompanied by occurrence of organizational and technical issues related with security (general system, information, economic, and personal type), with balanced natural and culture-related and not digital forms of cultivation of personal properties, for instance, patriotism [1,2]. It was required to formulate the concept of educational media space and management principles of dynamic open multidimensional digital education system. 
According to the theory of innovation provision and on the basis of management of logistic systems [8], it can be concluded that in terms of principles of system dynamics, the resource, engineering and legal provision of the formed media environment of education is similar to economic processes. Therefore, the integer (in many senses) multidimensional media space, as well as as its single units are characterized by properties and content similar to those of elements of territorially distributed logistic system [8], which should be adjusted and estimated, for instance, to prevent system risks.

One of the possible instruments of formal description of such systems is evaluating rating based on combination of indicators, providing more precise estimation for decision makers than official status or estimation by a single parameter [9]. For qualitative estimations using this method, it would reasonable to introduce clear gradation of levels of integrative security [10] upon formation of information space of media environment in socio-economic sphere (Fig. 3).

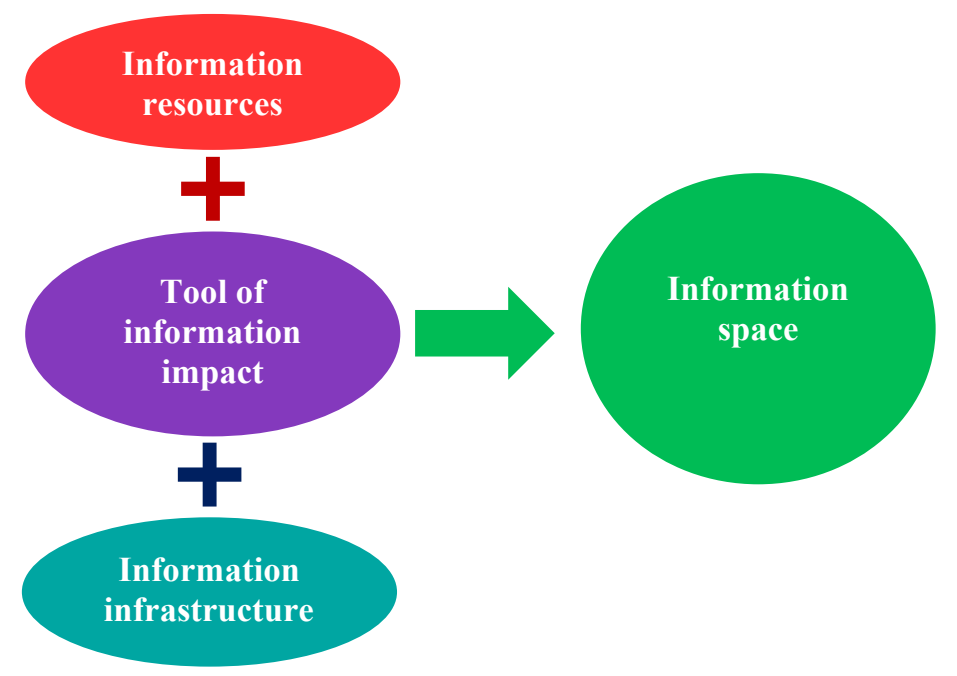

Fig. 3. Constituents of information space. 


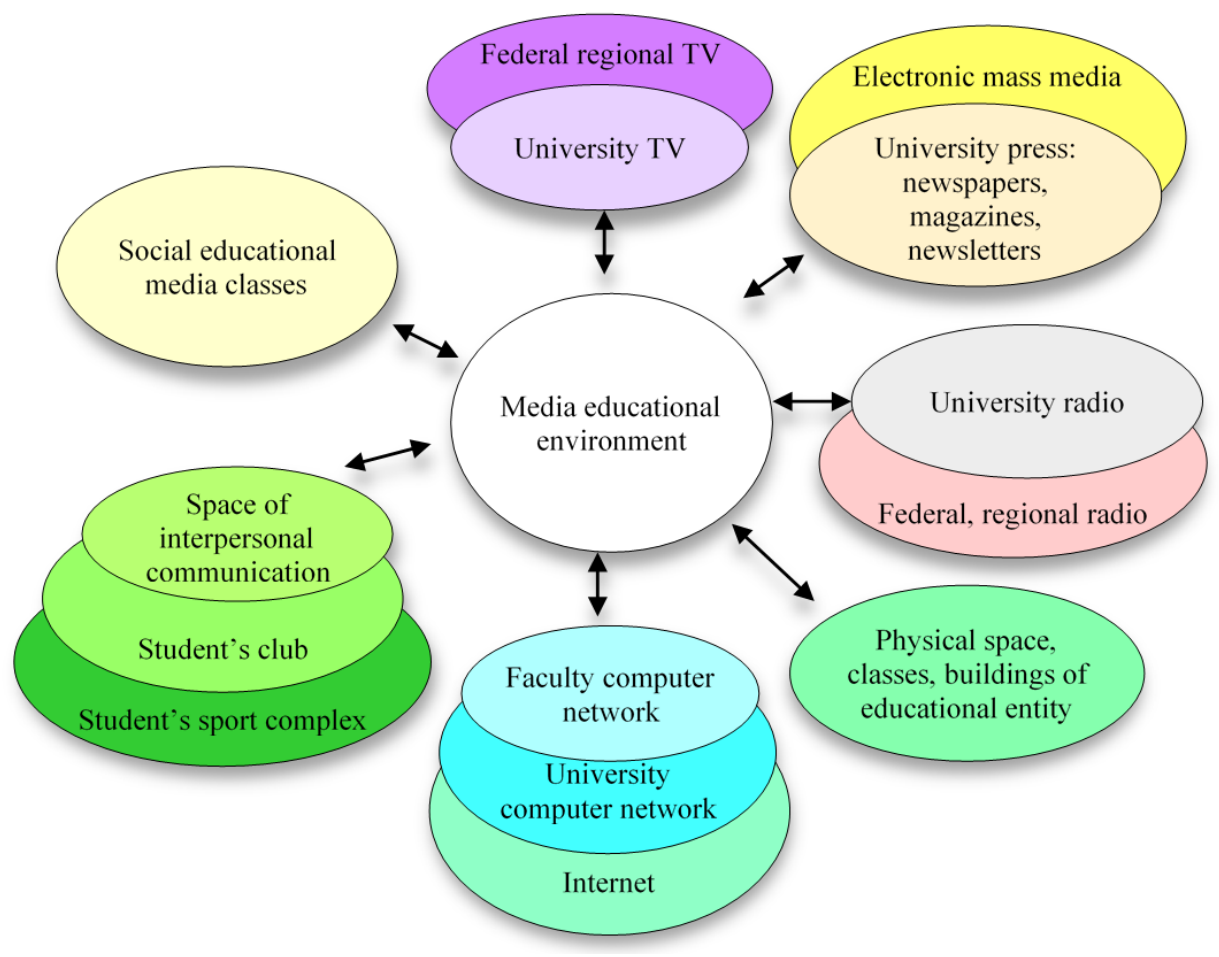

Fig. 4. Organization of media education environment.

Acquisition of goodwill by a subject of economic relations in the market of educational services, providing confidence of students, is achieved by web services, namely: web site of an educational entity (or integrated educational platform) [11].

The media environment itself is a complex structured system, management of its each element requires for methodological recommendations, which assumes availability of reserves for its subsequent resource optimization [12].

Formation of media space is conjugated with serious educational risks [13]. Risk management is a global multidimensional dynamic process deployed in time and complicated by random fluctuations of its meaningful parameters [14]. In order to improve the efficiency, the function of risk management can be transferred to decision makers working on the basis of consensus [15].

The media space of integer educational system during its development (when formalized data about applied technologies and degree of their implementation are available for decision makers) should possess at all stages of its life cycle protection against possible leakages and distortions of circulating data flows. These processes can be managed by adjustment of dynamic contour flows in the nodes of logistic system [8]. Based on these principles, the management of innovation, legal, documentation, engineering and other types of flows would allow to obtain educational platforms of proper quality with hard- and software adjustable for final user; hence, the education becomes adaptive [16]. Further stage of development of such educational system can be inclusion of all hierarchical levels of education into digitization upon their internal structuring (probably, by fractal harmonizing invariants).

Due to increase in the resource consumption upon sharp demographic growth, there occurred catastrophic shift of biosphere equilibrium towards human, domestic animals and plants (due to other fauna and flora). Technogenic activity modified biosphere creating 
ionosphere. Dynamic equilibrium was created in Earth biosphere: reprocessed natural resources were timely and completely recovered with preservation of planetary biomass. Previous civilizations violated this principle and the planet was cleansed of them (Gaia paradigm).

In the course of social evolution, a new form of community and human interaction appeared: state. In their progress the states occupied mentally and physically territories, filling the space of senses with thought forms of their citizens (as carriers of statist and cultural patterns). This was the growth, with strengthening and separation, of Egregore of state: a fractal mental condensate created by human conceptual community. Egregore is also a field (algorithmic energy information) formation, soliton.

The forms of interaction between egregore and human, according to K.V. Titov [17], are illustrated in Fig. 5. The best of them are superegregorial and non-egregorial positions, allowing to safely gain profit from communications with egregores upon preservation of will and thinking. It is known for long that philosophers create Gods (egregores of religions) to oppress profanes, women and slaves. Religions (as sects) can be established by visioners capturing the mood of masses. The egregors of religions are gradually being obscured by the negative thoughts and deeds of the flock, as a consequence they are either reformed, or adepts leave them (the cult is fading).

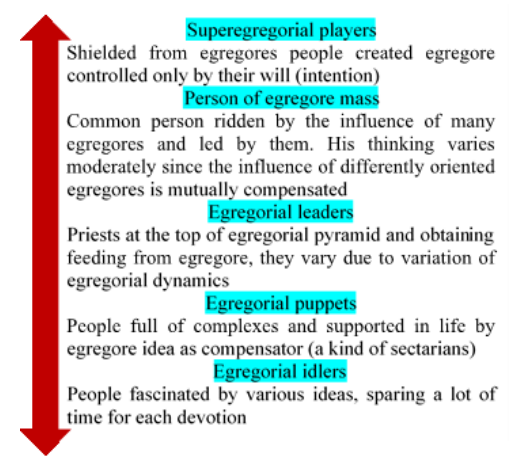

Fig. 5. Human roles upon interaction with egregore.

People are overwhelmed by passions (anger, aggression, fear, etc.), caused by inductive affection (driven by aggressive TV shows and news oriented at bulk audience), which leads in particular to destruction of thesaurus of linguistic identity, that is, its value concepts. During the crisis mental binding of many people is destroyed, stipulated by connections to various mental structures purposefully cultivated during learning (egregores and thought forms; firstly, powerful and rather aggressive state egregors and dominating religion). Identification of the mentioned hazards and risks, development of methods of counteractions require for special methodological cognitive approaches (for instance, on the basis of information ecology, ethnofunctional methods, emotive psycholinguistics, etc.) [1, $2,14]$.

The world is disturbed by continuous hybrid wars, including informational, consciental wars, destroying language concepts, spiritual and moral traditions and values, neutralizing senses and notions, entrenching upon identity of personality and nation, their mentality. Mentality is the philosophy of life in terms of categories and forms of native language, combining during cognition intellectual, spiritual, and volitional properties of national character in its typical embodiments [18]. This nonmilitary toolkit is dangerous by the fact that the impacts are percepted by community as motion along the road of democracy, tolerance, etc. The distance learning does not contain the elements of personal interactions, live communication, which can destructively influence the students due to external locus of 
personality formation, its value-based senses and backgrounds. COVID-19 has initiated other forms of aggression: neurowars, which vary behavioral models, volitional endeavors, emotional and behavioral settings, and moral psychic state of people as opposed to information consciental wars, which vary mentality [1, 2]. The COVID-19 situation implements the principles of neurowars, for instance, according to the concept Winning in a Complex World: 2020-2040 from the National Security Strategy (United States) [19]. According to this doctrine "...confrontation will take place in five battle fields (land, water, air, space, and cyber space) and in seven spheres: military actions, financial and economic conflicts, external political struggle, influence on internal policy, information, behavioral (for instance, COVID-19), and technological wars [7].

Under the conditions of digital society, the formation of personality mentality requires for existence of internal locus of control based on traditional national cultural and historical values, consolidated in the categories and forms of language as well as complying with the principles of nature and culture reasonability (environmental safety). Political technologies of nation destruction are based on transfer of aggression to information network space from military geographical space. Now the mental sphere (nation mentality, national and cultural identity, traditions, habits, etc.) is the battle field in consciental war $[1,2]$.

\section{Conclusion}

The trends of development of informational educational environment were analyzed as a function of maturity of social institutions, COVID-19, ecology of information space, degree of informatization of society, role and composition of suprapersonal (egregorial) structures, oriented at distortion of mentality of a personality and nation.

The role of mental structures should be accounted for upon provision of efficient control of dynamics of educational processes, which can be implemented by continuous application of decision makers upon working in aggressive emotional information environments of basic events relating to the spheres of economic and information safety and to ecology of media space.

It is required to develop new methods of risk management upon formation of educational environment (with consideration for interests of personal and national safety, information ecology, etc.), since digital information nonmilitary impact is the most important hazard of neurowars, because it is accepted by community as required progress, which requires for further scientific research devoted to prevent similar urgent hazards.

\section{References}

1. M.V. Saltykova, Nauchnyye i obrazovatelnyye problemy grazhdanskoy zashchity, 3(30), 97-104 (2016)

2. M.V. Saltykova, Bulletin of the Moscow International Academy, 2, 144-154 (2018)

3. O.V. Belitskaya, Development of pedagogically oriented media space of a professional educational organization: dis. ... cand. ped. Sciences (Saratov, 2015)

4. A.N. Makarenko, L.G. Smyshlyayeva, N.N. Minayev, O.M. Zamyatina, Higher education in Russia, 29(6), 113-121 (2020)

5. A.A. Vakhneeva, Ye.I. Davydova-Martynova, Open education, 21(6), 81-91 (2017)

6. I.A. Karlov et al., Sovremennaya analitika obrazovaniya, 4(34), 57 (2020)

7. Kommersant. The online education market is actively growing, URL: https://www.kommersant.ru/doc/4275439 (Date of access: 25.09.2020) 
8. A.S. Boyar-Sozonovitch, K.V. Pitelinskiy, D.A. Ermolatiy, Amazonia Investiga, 8(21), 6-13 (2019)

9. Ye.V. Brodovskaya, A.Yu. Dombrovskaya, R.V. Pyrma, A.A. Azarov, Bulletin of VolSU. Series 4, History. Regional studies. International relationships, 25(2), 268-283 (2020)

10. I.V. Ivanchenko et al., Bulletin of ASU, 3(223), 45-50 (2018)

11. O.O. Taranishin, N.A. Kalugina, G.O. Sakun, BIZNESINFORM, 11, 390-395(2019)

12. I.N. Demina, M.V. Shkondin, Voprosy teorii i praktiki zhurnalistiki, 5(2), 187-199 (2016)

13. T.S. Ilyina, N.Yu. Zakharov, Proceedings of Voronezh State University of Engineering Technologies, 4, 290-295 (2016)

14. K.V. Pitelinskiy, Bulletin of the Moscow Institute of Linguistics, 2, 107-111 (2013)

15. Ye.P. Kurkina, D.G. Shuvalova, Problemy nauki, 1(14), 63-69 (2017)

16. I.A. Krechetov, V.V. Romanenko, Educational Studies, 2, 252-277 (2020)

17. K.V. Titov, Egregors and archetypes of energy-informational civilization (Academy of Advanced Training and Professional Retraining of Educators, Moscow, 2006)

18. V.V. Kolesov, Life comes from the word ... (Zlatoust, St.Petersburg, 1999)

19. The White House, National Cyber Strategy of the Unites States of America. National Cyber Strategy - September 2018 (2018). Accessed on: December 20, 2020. [Online]. Available: https://www.whitehouse.gov/wp-content/up-loads/2018/09/National-CyberStrategy.pdf 